\title{
Schizophrenia in black Caribbeans living in the UK: an exploration of underlying causes of the high incidence rate
}

\author{
Rebecca Pinto, Mark Ashworth and Roger Jones
}

\begin{abstract}
The incidence of schizophrenia in black Caribbeans living in the UK is substantially higher than in the white British population. When first reported, these findings were assumed to be a first-generation migrant effect or merely the result of methodological artefacts associated with inconsistencies in the diagnosis of schizophrenia in black Caribbeans and doubts about population denominators. More recently, it has become clear that the incidence of schizophrenia, based on standardised diagnosis and sophisticated census methods, is higher still in secondgeneration black Caribbeans. The largest study to date has demonstrated a ninefold higher risk of schizophrenia in UKresident black Caribbeans: findings that are of concern to black Caribbean communities, to their GPs, and to health service managers responsible for resource allocation. A literature search was carried in order to explore possible reasons for the reported excess incidence of schizophrenia in UK-resident black Caribbeans. Competing hypotheses are reviewed and the paper concludes with a summary of specific social and psychological risk factors of significance within the black Caribbean community. Awareness of the factors associated with the onset and presentation of schizophrenia in black Caribbeans may help early diagnosis and rapid access to appropriate treatment which, in turn, appear to be related to improved long-term outcomes.

Keywords

aetiology; ethnicity; incidence; psychosis; schizophrenia.
\end{abstract}

R Pinto, BA (Hons), MSc, research associate;

M Ashworth, DM, MRCP, MRCGP, clinical senior lecturer; R Jones, DM, MA, FRCP, FRCGP, FMedSci, FFPHM, Wolfson professor of general practice, Department of General Practice and Primary Care, Division of Health and Social Care Research, King's College London.

Address for correspondence

Dr Mark Ashworth, Department of General Practice and Primary Care, King's College London, 5 Lambeth Walk,

London SE11 6SP.

E-mail: mark.ashworth@gp-G85053.nhs.uk

Submitted: 21 November 2007; Editor's response:

22 February 2008; final acceptance: 27 February 2008.

(c)British Journal of General Practice.

This article was originally online first. Cite this article as: Br J Gen Pract 2008; 58: 429-434. Advance online publication. DOI: $10.3399 /$ bjgp08X299254

\section{INTRODUCTION}

The median global prevalence of schizophrenia has been estimated at 4.6 (5th to 95th centiles, 1.9-10) per 1000 of the general population. ${ }^{1}$ In the UK, a GP with an average list size of just under 2000 patients can expect to care for about eight patients with schizophrenia, ${ }^{2}$ and possibly 12 if their practice is based in an urban area. ${ }^{3}$ Patients with schizophrenia consult their GP more than twice as frequently as the average patient, and it is the GP who is the health professional most likely to maintain contact and develop a long-term relationship with a patient with schizophrenia. ${ }^{4}$ Incidence rates are much lower than prevalence rates because schizophrenia commonly follows a protracted course. Global incidence rates are estimated to be 15.2 (5th to 95th centiles, 7.7-43.0) per $100000,{ }^{5}$ so GPs can, on average, expect to see one new case every 3 years.

Elevated incidence rates of schizophrenia in UK black Caribbeans have been consistently reported. ${ }^{6}$ The UK-based Aetiology and Ethnicity in Schizophrenia and Other Psychoses (价SOP) multisite (Bristol, south-east London, and Nottingham) study is one of the largest studies to examine ethnic variations in schizophrenia incidence..$^{7}$ In 2006, AESOP reported a ninefold increase in the risk of developing schizophrenia in black Caribbeans when compared with the white British population: the increased risk was 5.8 in black Africans and 1.4 in South Asians. ${ }^{8}$ These increased rates were derived from a population aged 16-64 years, with data for both sexes combined. Given these reports, a systematic literature search was conducted to explore possible factors accounting for these high rates of schizophrenia.

\section{METHOD}

A systematic search of MEDLINE ${ }^{\oplus}$, EMBASE, and PsychINFO databases was conducted employing the following search string: (schizophrenia OR psychos\$s) AND (ethni\$ OR African OR Caribbean OR migrant OR migration $O R$ immigrant $O R$ immigration $O R$ emigration OR emigrant) AND (epidemiolog\$ OR aetiolog\$ OR etiolog\$ OR incidence OR prevalence). 


\section{How this fits in}

Earlier studies have reported an increased incidence of schizophrenia in AfricanCaribbeans living in the UK, but methodological difficulties have influenced the interpretation of these findings. In the most robust UK study to date, the incidence of schizophrenia was found to be ninefold higher in black Caribbeans than in the white British population. The contributory risk factors appear to be a combination of social and psychological factors, which result in particular vulnerability to the development of schizophrenia. Increased awareness of these factors in the black Caribbean community may contribute to early diagnosis and rapid access to appropriate treatment, which in turn are likely to translate into improved long-term outcomes

The computerised search strategy was restricted to publications in the English language from 1987 to 2007. A total of 604 unique references were identified. Titles and abstracts were screened to discard irrelevant papers, and reference lists from non-discarded papers were checked for additional sources. A total of 231 relevant references were collated. Selected references are cited here; the full list of references is available from the authors.

The research concentrated mainly on incidence studies as these provide more insight into the potential triggers of schizophrenia, whereas prevalence studies may be harder to interpret; for example, the better prognosis of schizophrenia in developing countries results in correspondingly lower prevalence rates. ${ }^{9}$ Where possible, studies about black Caribbeans were searched for, as distinct from black Africans, although the terms 'Afro-Caribbean' in the earlier literature and 'African-Caribbean' more recently, have often been used in the literature to indicate both African and Caribbean groups.

\section{RESULTS}

The literature search revealed several hypotheses that might account for the high incidence of schizophrenia in black Caribbeans. These are summarised below.

\section{Genetic predisposition}

The most powerful risk factor for the development of schizophrenia is having an affected family member. The lifetime risk increases with genetic relatedness: $2 \%$ in third-degree relatives (first cousins); $2 \%$ (uncle/aunt) to $6 \%$ (half-siblings) in second-degree relatives; and $6 \%$ (parents) to $9 \%$ (siblings) to $13 \%$ (children) in first-degree relatives of affected individuals. ${ }^{10}$ For twins, the risk is higher still: $17 \%$ for dizygotic twins and $48 \%$ for monozygotic twins. ${ }^{10}$

Morbidity studies have found that parents of patients with schizophrenia and psychosis share similar levels of risk of developing schizophrenia, regardless of ethnicity. ${ }^{11,12}$ However, differences arise among siblings of affected patients according to ethnicity: the lifetime risk of developing schizophrenia in siblings of secondgeneration (UK-born) African-Caribbeans is $17 \%$, in first-generation African-Caribbeans it is $9 \%$, and in white British patients it is just $2 \% .^{11}$

If genetic predisposition is a substantial factor contributing to high incidence rates of schizophrenia in UK black Caribbeans, then high rates in their country of origin would also be expected. Studies conducted in the 1990s in Jamaica, Trinidad, and Barbados all report similar schizophrenia incidence rates to those found in the native UK population. ${ }^{13-15}$ Based on these studies, it appears that high rates of schizophrenia among black Caribbeans are a feature of the emigrated rather than the native community.

\section{Selective migration}

In 1932, Ødegärd found that Norwegians emigrating to the US were twice as likely to be admitted to hospital with first-onset schizophrenia as native-born Americans or Norwegians residing in Norway. ${ }^{16}$ Subsequent studies have confirmed the high incidence in migrants, demonstrating an overall relative risk of 2.7 in first-generation migrants and 4.5 in secondgeneration migrants. ${ }^{17}$

Ødegärd suggested that the raised schizophrenia rates in migrants occurred because those vulnerable to schizophrenia were predisposed to migrate..$^{16}$ If this were the case, we would expect to find diminishing schizophrenia rates in post-migration generations, whereas the opposite appears to apply to UK black Caribbeans: studies report higher rates in secondgeneration African-Caribbeans ${ }^{18}$ and other migrant groups. ${ }^{17}$ Furthermore, this hypothesis fails to explain why groups such as South Asians, who share the experience of migration, do not have comparably high rates of schizophrenia, or why the rate of schizophrenia in Surinam was not diminished when over one-third of the population migrated to the Netherlands during the 1970s. ${ }^{19}$

\section{Misdiagnosis}

Early schizophrenia incidence studies did not employ standardised diagnostic criteria, often did not adjust for age and socioeconomic status, and used retrospective case finding and inaccurate population denominators (undercounting of resident ethnic minorities). These methodological problems led to suggestions that excess rates of schizophrenia in the black Caribbean population were simply a methodological artefact. ${ }^{20}$ However, more-rigorous studies continue to report higher rates in UK black Caribbeans. For example, the EESOP study used population denominators derived from the 2001 national census (which included detailed ethnic group data and extensive adjustment for underenumeration), used standardised diagnoses of schizophrenia (International Classification of Disease [ICD]-10 criteria), and reached a diagnosis using 'consensus diagnostic groups' blinded to the ethnicity 
of the patient, and monitored for inter-rater and intercentre reliability. ${ }^{6}$

There are two explanations for misdiagnosis of schizophrenia - 'clinician bias', where psychiatrists misinterpret symptoms and overdiagnose schizophrenia, and 'cultural relativity', which describes the different ways in which schizophrenia is exhibited in different ethnic and cultural groups. ${ }^{21}$ The former argues that diagnostic bias by clinicians has inflated the true incidence in some ethnic groups. The latter argues that diagnostic differences are due to ethnic differences in the type of symptoms exhibited by schizophrenia.

Like many psychiatric diagnoses, the diagnosis of schizophrenia has a subjective element. To quantify the possibility of clinician bias, the diagnostic patterns of British and Jamaican psychiatrists have been compared..$^{22}$ The British psychiatrists classified $62 \%$ of black Caribbean patients as having schizophrenia, and the Jamaican psychiatrist recorded this diagnosis in $55 \%$ of these patients. Although a similar proportion of patients were classified as suffering from schizophrenia, at an individual level, agreement about the diagnosis of schizophrenia in black patients was only reached in $55 \%$ of cases. 'Race thinking' (resorting to cultural stereotypes), ${ }^{23}$ and examples of institutional racism within the mental health service ${ }^{24}$ (discriminatory practices within an organisation) may also result in a degree of clinician bias in everyday practice.

Cultural differences may also contribute to diagnostic error. At one extreme, Fernando has argued that existing cross-cultural incidence studies are flawed by the 'category fallacy' whereby western definitions of mental illness are applied to non-western cultures. ${ }^{25}$ Differences between cultures in the way hallucinations and religious experiences are regarded may have contributed to excess diagnoses in ethnic minority groups, as many non-western cultural beliefs could be considered to overlap with features of schizophrenia. $^{26}$ Nevertheless, the features of schizophrenia in western countries are broadly similar across ethnic groups, although one British study found affective symptoms to be more common in black Caribbeans, ${ }^{27}$ and a US study found an excess of paranoid symptoms in African-Americans. ${ }^{28}$

Although contributions of clinician bias and cultural relativity to higher rates of schizophrenia in UK black Caribbeans in a routine service setting cannot be excluded, they cannot account for research findings based on standardised diagnostic criteria and diagnostic assessments carried out by ethnicallymatched or blinded interviewers.

\section{Health service factors}

There are marked differences between AfricanCaribbean and white British patients with psychosis in terms of their pathways to care. Black Caribbeans typically follow adverse pathways during their first and subsequent episodes of psychosis: ${ }^{29}$ they are more likely to experience compulsory admission (odds ratio $[\mathrm{OR}]=2.30),{ }^{30}$ more likely to be referred to psychiatric services through the criminal justice system (OR = 1.98), ${ }^{31}$ less likely to be referred by their GP (OR = $0.48),{ }^{31}$ and have more protracted untreated symptoms during the first episode of psychosis ${ }^{32}$ (although another $\mathbb{E} S \mathrm{SOP}$ study $^{33}$ challenges previous findings of delays in treating psychosis in African-Caribbeans). These ethnic differences may bias results derived from secondary care studies, although they are unlikely to account for much of the ethnic difference in incidence, since over $80 \%$ of patients with schizophrenia require hospitalisation within 3 years of the onset of their psychotic symptoms. ${ }^{34}$

\section{Cannabis use}

Evidence is accumulating that cannabis use may be a potent trigger for the development of schizophrenia. A recent meta-analysis has calculated a pooled odds ratio of 2.1 for the development of schizophrenia in cannabis users, ${ }^{35}$ with the risk being dose related. ${ }^{36}$ Nevertheless, whether cannabis use is an aetiological factor in schizophrenia remains controversial.

However, there is no clear evidence that cannabis is a factor in the high incidence of schizophrenia in UK black Caribbeans. Psychosis among cannabis users does not appear to be more common in AfricanCaribbean patients compared to white British patients. ${ }^{37}$ Patients with schizophrenia in the Netherlands have broadly comparable patterns of cannabis use, regardless of whether they are from the native Dutch population or various migrant groups with high schizophrenia rates such as Moroccans and Surinamese. ${ }^{38}$ However, case managers surveyed in south London ${ }^{39}$ reported that black British-born patients with schizophrenia were significantly more likely to be using cannabis than white British patients $(\mathrm{OR}=4.8),{ }^{39}$ whereas black Africans and black Caribbeans born abroad were less likely to use cannabis (OR $=0.8$ ), suggesting that cannabis may play a role in secondand subsequent-generation African-Caribbeans. Ethnic differences in cannabis use among those who develop schizophrenia have been poorly researched in recent years, and there is a need for studies that include data on more-potent derivatives of cannabis such as 'skunk'.

\section{Social factors}

The association of schizophrenia with unemployment, poverty, and lower social class is well known, but this association appears to be more related to social selection (downward social drift of those with schizophrenia or predisposed to schizophrenia) than social causation (schizophrenia triggered by socioeconomic adversity). ${ }^{40}$ Urbanicity itself is 
associated with the incidence of schizophrenia, even allowing for confounding by known socioeconomic indicators, with growing up in an urban environment increasing the risk of developing schizophrenia later on in life by a factor of around 1.7.11

Since most UK black Caribbeans live in inner-city areas, and growing up in an urban environment contributes to the risk of schizophrenia, it can be argued that undetermined factors operating in an urban environment may account for some of the ethnic variations in incidence.

One factor that has attracted much recent research attention relates to the concept of social capital. Social capital has variously been described as the investment that people make to life within the local community, or 'the glue that holds society together'. ${ }^{42}$ Measures of social capital (voter turnout) and social cohesion (ethnic fragmentation) have been linked with schizophrenia incidence, ${ }^{43}$ and may therefore contribute to the raised rates in black Caribbeans. Evidence is accumulating that the most socially disorganised neighbourhoods, rather than the poorest neighbourhoods, have the highest incidence of schizophrenia, ${ }^{43}$ and these may be the areas where black Caribbeans are more likely to live.

Levels of social and family support may also play a role in the excess incidence of schizophrenia in black Caribbeans. In the ÆESOP study, parental separation and loss before the age of 16 years were found to be strongly associated with the onset of psychosis (OR = 3.4 and 3.2 , respectively). ${ }^{44}$ Separation, particularly paternal separation, was more common in black Caribbeans than in the white British population. ${ }^{44}$ In contrast, South Asian family structures are typically close-knit and supportive, ${ }^{45}$ which may offer a protective effect against the development of schizophrenia. Similarly, the Turkish community in the Netherlands has low rates of schizophrenia compared to other immigrant groups and it too is viewed as being socially cohesive, with low rates of single-parent households. ${ }^{46}$

African-Caribbeans living in predominantly white neighbourhoods have been found to have a higher incidence of schizophrenia. This has been termed, the 'ethnic density' effect, ${ }^{47}$ and may be another expression of social isolation. ${ }^{48}$ Individuals living in areas where their own ethnic group constitutes a smaller proportion of the local population have been reported to feel excluded from local social networks and dependent on geographically dispersed, culturally specific, facilities. ${ }^{49}$ Compared to the UK AfricanCaribbean community, South Asians are less dispersed and less likely to be socially isolated, which may contribute to the relatively low rates of schizophrenia in South Asians. ${ }^{50}$ McKenzie et al have suggested that the ethnic density effect may be explained by higher levels of social capital in ethnicallydense communities. ${ }^{42}$

\section{Psychological factors}

Adversity in many forms appears to contribute to higher rates of schizophrenia, but attitudes to adversity are also likely to play a role. For example, despite there being no difference in the frequency of adverse life events, African-Caribbeans with psychosis are more likely to perceive their adversity as part of a pattern of racial discrimination or as being caused by others and intended (external attribution), rather than being merely the result of ill-fortune without any personal dimension. ${ }^{51}$ These attitudes may make individuals more prone to develop schizophrenia by generating a paranoid or defensive outlook on life. ${ }^{52}$ Continual experience of 'social defeat' or 'outsider status' in a competitive society has also been thought to predispose some people to schizophrenia. ${ }^{17}$ The association may be one of reverse causality whereby mild paranoia or external attributional styles are themselves the early features of a latent schizophrenia. Prospective studies may be useful in determining the direction of causality; in one longitudinal study, perceived discrimination over a 3year period predicted the subsequent development of delusional ideas, and this association was found to bear a dose-response relationship, suggesting that discrimination itself may be a trigger to the subsequent development of schizophrenia. ${ }^{53}$ However, auditory hallucinations were not associated with preceding discriminatory experiences.

Cross-cultural studies in the general UK population shed some light on possible psychological factors. Paranoid ideas may be more common in AfricanCaribbeans than in the white population in the UK. ${ }^{54}$ Hallucinatory experiences are also more commonly reported in the African-Caribbean community (10\%), compared to white (4\%) and South Asian (2\%) populations. ${ }^{55}$ If indeed there is a spectrum of symptoms within a population that eventually produce full-blown schizophrenia in some individuals, then the precursors appear to be more prevalent in AfricanCaribbeans.

The interplay between schizophrenia, cognitive processes, and social discrimination may be more complex still. When migrants from countries where the majority of the population is black settle in countries with a white host population, they have a higher incidence rate of schizophrenia (relative risk, 4.8) than migrants from predominantly white countries (relative risk, 2.3) and also than migrants from the Middle East, defined as 'neither black nor white' (relative risk, 2.2). ${ }^{17}$ These findings suggest that migrants whose skin colour is substantially darker than that of the native population are more vulnerable to schizophrenia. Racism based on the darkness of skin colour rather 
than merely on ethnic grouping may account for these findings, and perceptions of racism have been found to increase according to skin darkness. ${ }^{56}$ Larger visible differences between an ethnic group and the host population may enhance an 'outsider status'.

Psychological factors may also operate at a group rather than individual level. Ethnic minorities differ in the degree to which they are stigmatised by the native population. Members of each ethnic minority group develop an awareness of their identity and status within society. Belonging to an ethnic minority group which perceives high levels of discrimination increases the risk of developing schizophrenia (incidence rate ratios of 4.0 and 1.2 for ethnic minority groups perceiving high and low discrimination, respectively). ${ }^{57}$

\section{CONCLUSION}

The high level of schizophrenia in black Caribbeans living in the UK probably reflects the interaction of multiple risk factors, many of which cluster in the black Caribbean community in the UK. Particularly significant factors appear to be the combination of isolation and exclusion, both within society (living in areas of low ethnic density and reduced participation in society) and within the family (family break-up and paternal separation). These factors seem to be more powerful than socioeconomic disadvantage, which is more likely to be a consequence than causal. Racism itself may contribute to social exclusion, increasing the vulnerability to schizophrenia. Biological or genetic susceptibility do not appear to explain high rates of schizophrenia in black Caribbeans. More research is needed about the role of cannabis, particularly in its more potent forms, and whether this contributes to the excess of schizophrenia in black Caribbeans.

Understanding of high rates of schizophrenia in some ethnic groups may be enhanced by an exploration of protective factors. South Asians have experienced migration, problems with cultural assimilation, and sociodemographic disadvantage, and yet they experience only marginally higher rates of schizophrenia than those of the white British population. Further study is needed on whether social cohesion and strong family support or other factors within the South Asian community confer a protective effect.

\section{Funding body}

This work was supported by a grant from the Guy's and St Thomas' Charity (R041047)

\section{Competing interests}

The authors have stated that there are none

\section{Acknowledgements}

We would like to thank Professor Philip McGuire for helpful comments on this manuscript.

\section{Discuss this article}

Contribute and read comments about this article on the

Discussion Forum: http://www.rcgp.org.uk/bjgp-discuss

\section{REFERENCES}

1. Saha S, Chant D, Welham, et al. A systematic review of the prevalence of schizophrenia. PLoS Med 2005; 2(5): el4.

2. Kendrick T, Sibbald B, Burns T, Freeling P. Role of general practitioners in care of long term mentally ill patients. BMJ 1991; 302(6777): 508-510.

3. King M, Nazareth I. Community care of patients with schizophrenia: the role of the primary health care team. Br J Gen Pract 1996; 46(405): 231-237.

4. Burns T, Kendrick T. The primary care of patients with schizophrenia: a search for good practice. Br J Gen Pract 1997; 47(421): 515-520.

5. McGrath J, Saha S, Welham J, et al. A systematic review of the incidence of schizophrenia: the distribution of rates and the influence of sex, urbanicity, migrant status and methodology. BMC Med 2004; 2: 13.

6. Fearon P, Morgan C. Environmental factors in schizophrenia: the role of migrant studies. Schizophr Bull 2006; 32(3): 405-408.

7. Fearon, P, Kirkbride, J, Morgan, C, et al. Patterns of psychosis in black and white minority groups in urban UK: the ÆSOP study. Schizophr Bull 2005; 31(2): 222

8. Fearon P, Kirkbride J, Morgan C, et al. Incidence of schizophrenia and other psychoses in ethnic minority groups: results from the MRC ÆSOP Study. Psychol Med 2006; 36(11): 1541-1550.

9. Bresnahan M, Menezes P, Varma V, Susser E. Geographical variation in incidence, course and outcome of schizophrenia: a comparison of developing and developed countries. In: Murray RM, Jones PB, Susser E, et $\mathrm{al}$ (eds). The epidemiology of schizophrenia. Cambridge: Cambridge University Press, 2003: 5-17.

10. Gottesman II. Schizophrenia genesis: the origins of madness. New York: WH Freeman, 1991

11. Sugarman PA, Craufurd D. Schizophrenia in the Afro-Caribbean community. Br J Psychiatry 1994; 164(4): 474-480.

12. Hutchinson G, Takei N, Fahy TA, et al. Morbid risk of schizophrenia in firstdegree relatives of white and African-Caribbean patients with psychosis. $\mathrm{Br} J$ Psychiatry 1996; 169(6): 776-780.

13. Hickling FW, Rodgers-Johnson P. The incidence of first contact schizophrenia in Jamaica. Br J Psychiatry 1995; 167(2): 193-196.

14. Bhugra D, Hilwig M, Hossein B. First-contact incidence rates of schizophrenia in Trinidad and one-year follow-up. Br J Psychiatry 1996. 169(5): 587-592.

15. Mahy GE, Mallett R, Leff J, Bhugra D. First-contact incidence rate of schizophrenia on Barbados. Br J Psychiatry 1999; 175: 28-33.

16. Ødegärd O. Emigration and insanity: a study of mental disease among Norwegian-born population in Minnesota. Acta Psychiatr Scand 1932; 7(suppl 4): 1-206.

17. Cantor-Graae E, Selten JP. Schizophrenia and migration: a meta-analysis and review. Am J Psychiatry 2005; 162(1): 12-24.

18. Harrison G, Owens D, Holton A, et al. A prospective study of severe mental disorder in Afro-Caribbean patients. Psychol Med 1988; 18(3): 643-657.

19. Hanoeman M, Selten J-P, Kahn RS. Incidence of schizophrenia in Surinam. Schizophr Res 2002; 54(3): 219-221.

20. Sashidharan SP. Afro-Caribbeans and schizophrenia: the ethnic vulnerability hypothesis re-examined. Int Rev Psychiatry 1993; 5(2/3): 129-144.

21. Whaley AL. Ethnicity/race, paranoia, and psychiatric diagnoses: clinician bias versus sociocultural differences. J Psychopathol Behav Assess 1997; 19(1): $1-20$.

22. Hickling FW, McKenzie K, Mullen R, et al. A Jamaican psychiatrist evaluates diagnosis at a London psychiatric hospital. Br J Psychiatry 1999; 175: 283-285.

23. Lewis G, Croft-Jeffreys, David A. Are British psychiatrists racist? Br J Psychiatry 1990; 157: 410-415.

24. McKenzie K, Bhui K. Institutional racism in mental health care. BMJ 2007; 334(7595): 649-650.

25. Fernando S. Race and culture in psychiatry. London: Routledge, 1998.

26. Chandrasena R. Schneider's first rank symptoms: an international and interethnic comparative study. Acta Psychiatr Scand 1987; 76(5): 574-578.

27. Hutchinson G, Takei N, Sham P, et al. Factor analysis of symptoms in schizophrenia: differences between White and Caribbean patients in Camberwell. Psychol Med 1999; 29(3): 607-612.

28. Toch H, Adams K, Greene R. Ethnicity, disruptiveness, and emotional disorder among prison inmates. Crim Justice Behav 1987; 14(1): 93-109.

29. Bhui K, Stansfeld S, Hull S, et al. Ethnic variations in pathways to and use of specialist mental health services in the UK: systematic review. Br J Psychiatry 2003; 182: 105-116.

30. Morgan C, Mallett R, Hutchinson G, et al. Pathways to care and ethnicity. 1: sample characteristics and compulsory admission. Br J Psychiatry 2005; 186: 281-289. 
31. Morgan C, Mallett R, Hutchinson G, et al. Pathways to care and ethnicity. 2: source of referral and help-seeking. Br J Psychiatry 2005; 186: 290-296.

32. Harrison G, Holton A, Neilson D, et al. Severe mental disorder in AfroCaribbean patients: some social, demographic and service factors. Psychol Med 1989; 19(3): 683-696.

33. Morgan C, Fearon P, Hutchinson G, et al. Duration of untreated psychosis and ethnicity in the ÆSOP first-onset psychosis study. Psychol Med 2006; 36(2): 239-247.

34. Sipos A, Harrison G, Gunnell D, et al. Patterns and predictors of hospitalisation in first-episode psychosis. Br J Psychiatry 2001; 1778: 518-523.

35. Henquet C, Murray R, Linszen D, van Os J. The environment and schizophrenia: the role of cannabis use. Schizophr Bull 2005; 31(3): 608-612.

36. Van Os J, Bak M, Bijl RV, et al. Cannabis use and psychosis: a longitudinal population-based study. Am J Epidemiol 2002; 156(4): 319-327.

37. McGuire PK, Jones P, Harvey I, et al. Cannabis and acute psychosis. Schizophr Res 1994; 13(2): 161-168.

38. Veen N, Selten J-P, Hoek HW, et al. Use of illicit substances in a psychosis incidence cohort: a comparison among different ethnic groups in the Netherlands. Acta Psychiatr Scand 2002; 105(6): 440-443.

39. Afuwape SA, Johnson S, Craig TJK, et al. Ethnic differences among a community cohort of individuals with dual diagnosis in South London.J Ment Health 2006; 15(5): 551-567.

40. Dohrenwend BP, Levav I, Shrout PE, et al. Socioeconomic status and psychiatric disorders: the causation-selection issue. Science 1992; 255(5047): 946-952.

41. Krabbendam L, van Os J. Schizophrenia and urbanicity: a major environmental influence - conditional on genetic risk. Schizophr Bull 2005; 31(4): 795-799.

42. McKenzie K, Whitley R, Weich S. Social capital and mental health. $\mathrm{Br} J$ Psychiatry 2002; 181: 280-283.

43. Kirkbride JB, Morgan C, Fearon P, et al. Neighbourhood-level effects on psychoses: re-examining the role of context. Psychol Med 2007; 37(10): 1413-1425.

44. Morgan C, Kirkbride J, Leff J. Parental separation, loss and psychosis in different ethnic groups: a case-control study. Psychol Med 2007; 37(4): $495-503$.

45. Cochrane R, Bal SS. Migration and schizophrenia: an examination of five hypotheses. Soc Psychiatry Psychiatr Epipdemiol 1987; 22(4): 181-191.

46. Selten JP, Veen N, Feller W, et al. Incidence of psychotic disorders in immigrant groups to The Netherlands. Br J Psychiatry 2001; 178: 367-372.

47. Bhugra D, Jones P. Migration and mental illness. Adv Psychiatr Treat 2001; 7(3): 216-223.

48. Boydell J, van Os J, McKenzie K. Incidence of schizophrenia in ethnic minorities in London: ecological study into interactions with environment. BMJ 2001; 323(7325): 1336.

49. Whitley R, Prince M, McKenzie K, Stewart R. Exploring the ethnic density effect: a qualitative study of a London electoral ward. Int $J$ Soc Psychiatry 2006; 52(4): 376-391.

50. Bhugra D, Leff J, Mallett R, et al. Incidence and outcome of schizophrenia in whites, African-Caribbeans and Asians in London. Psychol Med 1997; 27(4): 791-798.

51. Gilvarry C, Walsh E, Samele C, et al. Life events and perceptions of racism in a sample of community care patients with psychotic illnesses. Soc Psychiatry Psychiatr Epidemiol 1999; 24(10): 49-56.

52. Kinderman P, Bentall RP. Self-discrepancies and persecutory delusions: evidence for a model of paranoid ideation. J Abnorm Psychol 1996; 105(1): 106-113.

53. Janssen I, Hanssen M, Bak M, et al. Discrimination and delusional ideation. Br J Psychiatry 2003; 182: 71-76.

54. Sharpley MS, Peters ER. Ethnicity, class and schizotypy. Soc Psychiatry Psychiatr Epidemiol 1999; 34(10): 507-512.

55. Johns LC, Nazroo JY, Bebbington P, et al. Occurrence of hallucinatory experiences in a community sample and ethnic variations. Br J Psychiatry 2002; 180: 174-178.

56. Williams DR. Race, Socioeconomic status, and health: the added effects of racism and discrimination. Ann NY Acad Sci 1999; 896: 173-188.

57. Veling W, Seleten J-P, Susser E, et al. Discrimination and the incidence of psychotic disorders among ethnic minorities in The Netherlands. Int J Epidemiol 2007; 36(4): 761-768 